\title{
EISCAT observations of bursts of rapid flow in the high latitude dayside ionosphere
}

Article

Published Version

Todd, H., Bromage, B. J. I., Cowley, S. W. H., Lockwood, M., van Eyken, A. P. and Willis, D. M. (1986) EISCAT observations of bursts of rapid flow in the high latitude dayside ionosphere. Geophysical Research Letters, 13 (9). pp. 909-912. ISSN 0094-8276 doi: https://doi.org/10.1029/GL013i009p00909 Available at https://centaur.reading.ac.uk/38911/

It is advisable to refer to the publisher's version if you intend to cite from the work. See Guidance on citing.

Published version at: http://dx.doi.org/10.1029/GL013i009p00909

To link to this article DOI: http://dx.doi.org/10.1029/GL013i009p00909

Publisher: American Geophysical Union

All outputs in CentAUR are protected by Intellectual Property Rights law, including copyright law. Copyright and IPR is retained by the creators or other copyright holders. Terms and conditions for use of this material are defined in the End User Agreement.

www.reading.ac.uk/centaur 
Central Archive at the University of Reading

Reading's research outputs online 


\title{
EISCAT OBSERVATIONS OF BURSTS OF RAPID FLOW IN THE HIGH LATITUDE DAYSIDE IONOSPHERE
}

\author{
H. Todd ${ }^{1}$, B.J.I. Bromage ${ }^{2}$, S.W.H. Cowley ${ }^{1}$, M. Lockwood ${ }^{2}$, A.P. van Eyken ${ }^{2,3}$ and D.M. Willis ${ }^{2}$
}

Abstract. Observations are presented of short-lived, highly structured bursts of rapid plasma flow observed with the EISCAT radar in the high latitude dayside ionosphere. It is shown that the properties of the bursts are consistent with ionospheric perturbations caused by impulsive, localized reconnection at the Earth's magnetopause, i.e. by flux transfer events.

\section{Introduction}

Spacecraft observations near the Earth's dayside magnetopause have shown that the processes which couple magnetospheric and magnetosheath plasmas across the boundary often have a localized and impulsive character, particularly when the $B_{z}$ component of the interplanetary magnetic field (IMF) is small or negative [Russell and Elphic, 1979; Sckopke et a1., 1981; Rijnbeek et a1., 1984]. The "pulses" of boundary layer plasma which are then observed have been interpreted by Cowley (1982) and Paschmann et al. (1982) as resulting from localized, impulsive reconnection (i.e. flux transfer events (FTEs)), but as the signature of "impulsive penetration" by e.g. Lundin and Dubinin (1984). Cowley (1984, 1986) and Southwood (1985) have given brief theoretical descriptions of the expected ionospheric effects, showing that their size should be $\sim 300 \mathrm{~km}$, at least for the largest magnetopause events. Bursts of flow from the dayside auroral zone into the polar cap have been observed during periods of high magnetic activity using the STARE data by Goertz et al. (1985). The most prominent of their events had a spatial scale of $\sim 200 \mathrm{~km}$ and with peak flows $\sim 2 \mathrm{~km} \mathrm{~s}^{-1}$, the main perturbation lasted for $\sim 2 \mathrm{~min}$ at any one location. These authors related their observations to FTEs, and pointed out that "impulsive penetration" would give rise to equatorward-directed bursts, contrary to their observations.

In initial results from the "POLAR" EISCAT (European Incoherent Scatter) radar experiment, van Eyken et al. (1984) also reported observations of a poleward-directed flow burst. This event appeared to have a larger spatial scale (more than $400 \mathrm{~km}$ ), a longer time scale $(\sim 10 \mathrm{~min})$ and lower flow speeds $\left(\sim 300 \mathrm{~m} \mathrm{~s}^{-1}\right)$ than those reported by Goertz et al. (1985). Subsequent POLAR experiments (Willis et a1., 1986) detected bursts whose parameters are

\footnotetext{
${ }_{2}^{1}$ Blackett Laboratory, Imperial College

2 Rutherford Appleton Laboratory.

${ }^{3}$ Now at Millstone Hill Radar
}

Copyright 1986 by the American Geophysical Union.

Paper number 6L 6248

$0094-8276 / 86 / 006 \mathrm{~L}-6248 \$ 03.00$ more similar to the largest of those described by Goertz et al. (1985). Here we present data encompassing two wel1-defined burst events. We show that the data are consistent with observations of poleward-moving twin vortices as predicted for FTEs by Southwood (1985).

\section{The EISCAT POLAR Experiment}

The main aim of the POLAR experiment is the measurement of flows in the dayside auroral zone and polar cusp far to the north of the transmitter site at Troms $\not$, with good time resolution [van Eyken et al., 1984; Will is et al., 1986l. At these latitudes the geometry of the tristatic EISCAT system is unfavourable, so the beam-swinging technique is employed. The radar is pointed at a low elevation angle $\left(21.5^{\circ}\right)$ and swung successively between azimuths $12^{\circ}$ on either side of geographic azimuth $344^{\circ}$, approximately the direction of the L-shell meridian at Troms $\varnothing$. Useful return signals are obtained where the beam passes through the high density F-region ionosphere, corresponding typically to the first 5 to 10 of the range gates employed, depending upon geophysical conditions. The centres of the gates are separated by $75 \mathrm{~km}$ along the beam. Here we present data from the first 5 range gates whose centres span the invariant latitude range from $70.8^{\circ}$ to $73.2^{\circ}$ at steps of $0.6^{\circ}$ corresponding to heights of 211 to $346 \mathrm{~km}$. The dwell time at each of the two azimuth settings is $2 \mathrm{~min}$, and the continuously integrated data are recorded every $15 \mathrm{sec}$. Rotation to the new azimuth then takes $30 \mathrm{sec}$, so that the full cycle of two dwell periods and two movements is $5 \mathrm{~min}$. Here we present data at the full $15 \mathrm{sec}$ resolution, which is comparable with the time resolution of the STARE system.

\section{Observations}

The data discussed here are from one of a series of POLAR experiments conducted in coordination with AMPTE-UKS measurements in the solar wind [Willis et al., 1986]. They were obtained on 27 October 1984 during a period of moderate magnetic activity $\left(\mathrm{K}_{\mathrm{p}}=2+\right)$. Away from midnight, the flows observed at POLAR latitudes generally correspond to the auroral zone return flows of the usual twincel1 convection pattern. On 27 October fast eastward flows on the dawn-side had retreated poleward of the field of view after $0310 \mathrm{UT}$ (add 2.5 hours for MLT), and fast westward flows in the dusk cell were not observed until 1120 UT, following a sharp southward turning of the IMF [Rishbeth et al., 1985]. Between these times the POLAR field of view was thus located generally equatorward of the main flow cells, though sporadic flows were observed, which were mainly eastward before 0600 UT and westward thereafter. 


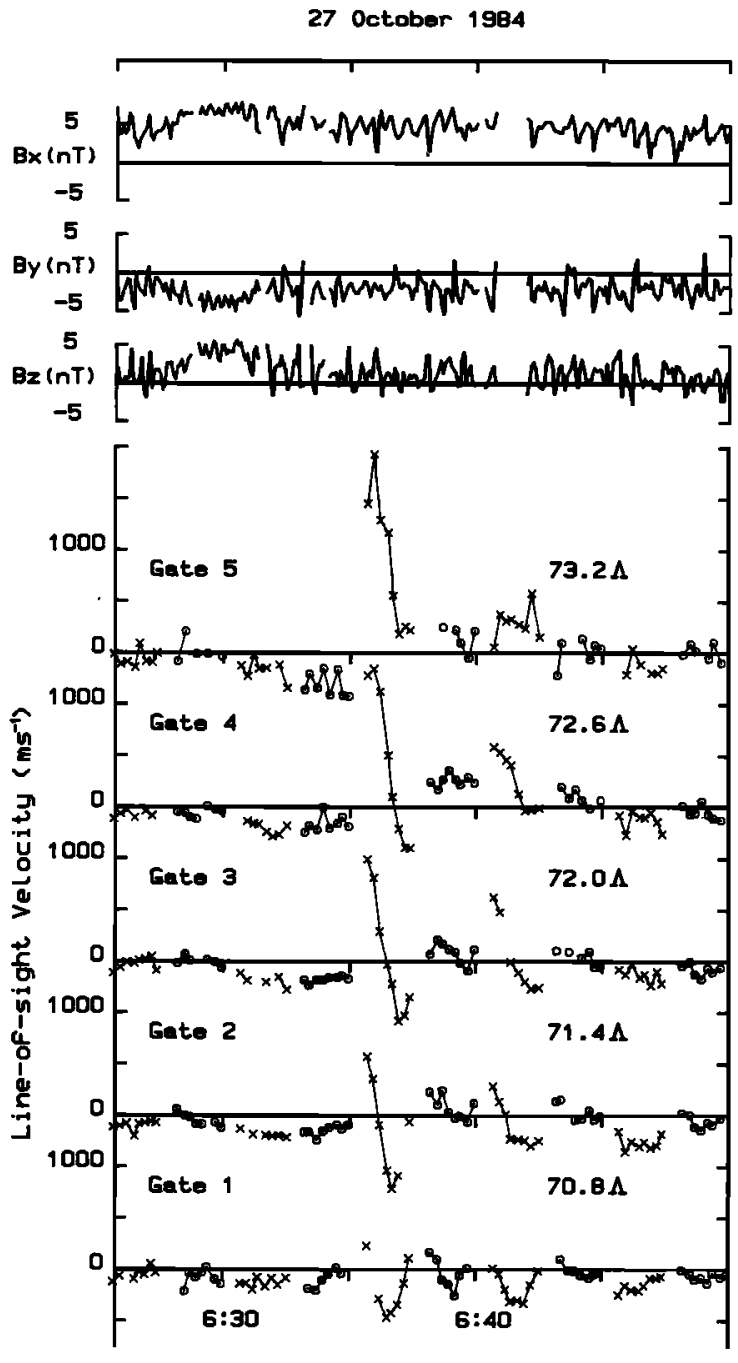

Univaras 1 Time

Fig. 1. AMPTE-UKS IMF data (top) and EISCAT POLAR data (bottom) for the interval 0626 to 0650 UT on 27 October 1984. The UKS magnetometer data are $5 \mathrm{sec}$ averages and plotted as GSM components. The UKS spacecraft was located in the solar wind at GSM (X,Y,Z) $=(17.1,-7.0,3.5) \mathrm{R}_{\mathrm{E}}$ during the interval. The POLAR data consist of $15 \mathrm{sec}$ averages of $1-0-s$ velocities measured $12^{\circ}$ to the west (circles) and $12^{\circ}$ to the east (crosses) of local magnetic north at the transmitter site at Troms $\phi$. Positive values indicate flow away from the radar (approximately northward).

Figure 1 shows AMPTE-UKS IMF and EISCAT POLAR data for the period 0626 to $0650 \mathrm{UT}$. The GSM components of the IMF ( $5 \mathrm{sec}$ averages) are shown at the top of the figure, and line of sight $(1-0-s)$ velocities from gates $1-5$ are shown in the lower part, positive values indicating flow away from the radar (approximately northward). Observations at the westerly and easterly beam positions (azimuths 1 and 2) are shown as circles and crosses respectively. The data thus consist of groups of eight circles or crosses ( 2 min dwell periods) separated by $30 \mathrm{sec}$ gaps while the antenna was moving. Points are missing when the curve fitting procedure used to obtain plasma parameters from the backscatter signal auto-correlation function failed to converge. Estimates of the probable errors in the 1-o-s velocities are typically $\pm 45,37,37,57$ and $102 \mathrm{~m} \mathrm{~s}^{-1}$ for gates 1 to 5 respectively.

Two similar bursts were observed in the interval 0635 to 0645 UT. They thus occurred in the period of sporadic dayside flows just after the predominant direction changed from eastward to westward. At the beginning of the interval shown in Figure 1 1-o-s speeds are smal1, typically $\sim 100-200 \mathrm{~m} \mathrm{~s}^{-1}$ or less, and remain so up to the end of the dwell period at azimuth 1 at 0635 UT. On turning to azimuth 2, at 0635:30 UT, however, a large discrete burst of flow is observed, which is directed initially poleward, reverses to become equatorward and then turns poleward once more. The measurements show that a similar pattern occurs in each range gate, but with a successive delay of approximately $20 \mathrm{sec}$ between each gate with increasing latitude (judging from the velocity reversal). The apparent propagation speed of the flow pattern along the radar line of sight is therefore $\sim 3.5 \mathrm{~km} \mathrm{~s}^{-1}$, rather faster than the peak poleward flows of $\sim 1.5$ to $2 \mathrm{~km} \mathrm{~s}^{-1}$ measured during the event. The subsequent dwell at azimuth 1 starting at 0638 UT then indicates the presence of moderate poleward flows of $\sim 200-300 \mathrm{~m} \mathrm{~s}^{-1}$, which generally decline to small values, though there is some indication that poleward flow begins to pick up again at the end of this dwell period. The following two dwell periods (0641 to 0645 UT) then show a repeat of the pattern, though with smaller speeds.

The initial development of these events appears to have occurred mainly in the $30 \mathrm{sec}$ intervals when the radar was moving towards azimuth 2, at $\sim 0635$ UT and $\sim 0640$ UT. Examination of the two $15 \mathrm{sec}$ data dumps acquired during the first of these intervals (not shown) indicates that poleward flows started to grow during the first $15 \mathrm{sec}$ interval while the radar was moving, and reached values similar to those shown at the beginning of the azimuth 2 dwell during the remainder of the swing. The development of the burst thus appears to have been very rapid indeed, an inference substantiated by examination of other bursts where the onset was more clearly recorded. We also note here that while sequences of two or three successive bursts are not uncommon in the POLAR data (as here), single bursts having the form of those shown have also been observed, thus supporting our interpretation in terms of two individual events rather than an intimately connected sequence. Concerning the size of the event, the perturbation clearly extends about $300 \mathrm{~km}$ longitudinally between azimuths 1 and 2. From the number of gates in which the flows are observed the latitudinal extent is also at least $300 \mathrm{~km}$.

The IMF data in Figure 1 show an average $B_{z}$ close to zero in the presence of largeamplitude waves upstream from the Earth's bow shock. Simultaneous plasma data (not shown) from the IRM spacecraft (located close to the 


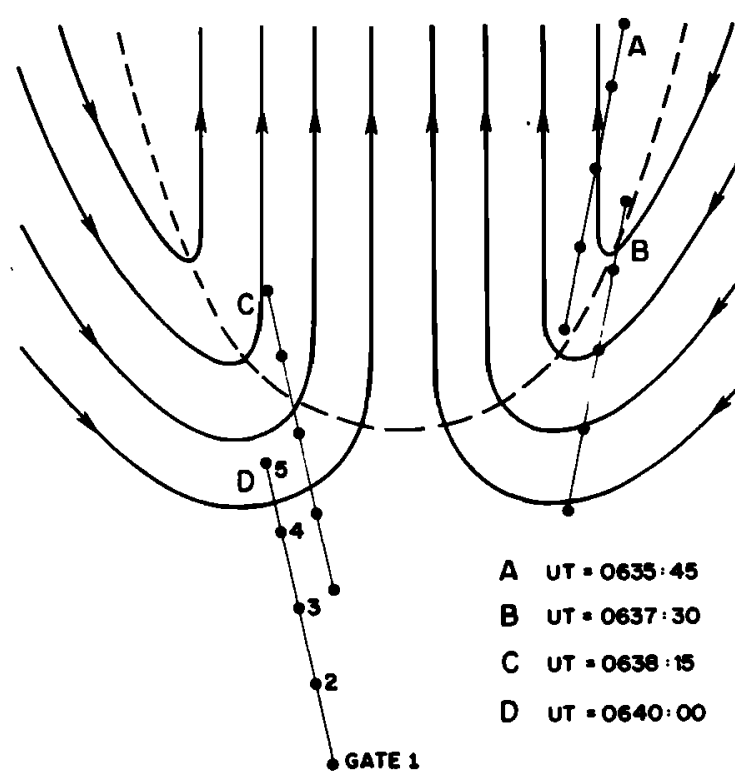

Fig. 2. Sketch of the ionospheric disturbance flow system resulting from localized, impulsive reconnection at the magnetopause. Solid lines show streamlines, while the dashed line shows the boundary of open and closed field lines. The straight lines indicate the postulated position of the radar beam at the beginning and end of the two 2 min dwells encompassing the burst interval, the dots showing the centres of the range gates.

UKS) indicate a steady solar wind flow (G. Paschmann, personal communication, 1986). The bursts were not, therefore, associated with large discrete changes in solar wind or IMF parameters.

\section{Discussion}

In this section we argue that the data may be consistently interpreted in terms of ionospheric perturbations resulting from rapid, localized reconnection at the Earth's magnetopause (i.e. FTEs). The burst events were observed in the region of dayside eastwest flow reversal, which should map magnetically to the main magnetopause interaction region. They also occurred while $\mathrm{B}_{z}$ was weakly positive, and while this is not optimum for reconnection, both quasi-steady reconnection and FTEs have been observed in situ at the magnetopause under this condition [Sonnerup et al., 1981; Rijnbeek et al., 1984].

During a localized burst of rapid reconnection the boundary of open field lines in the ionosphere will move rapidly equatorward, forming a corrugation. Within the corrugation the flow will respond to the stresses imposed by the magnetosheath flow and field and will in general have east-west as well as poleward components. In the present case the pre-noon local time suggests westward and poleward flows, but the negative IMF $B_{y}$ values prevailing (Figure 1) would indicate the presence of eastward-directed magnetic stresses on open field lines in the northern hemisphere which would oppose the westward motion.
Expectations regarding the east-west motion are thus unclear and predominantly polewarddirected flows are a likely outcome. After reconnection has ceased the boundary of open field lines will move with the velocity of the open flux tubes within the corrugation. Continuity of the incompressible ionospheric flow also requires the presence of flow perturbations in the region surrounding the open flux corrugation of magnitude similar to that within the corrugation itself. The overall flow will then form a localized twinvortex as shown in Figure 2 [Southwood, 1985]. The solid lines show the streamlines, while the dashed line shows the boundary of the open flux region.

Considering only the first and largest flow burst in detail, we propose that the corrugation expanded rapidly across the field of view between 0635:00 and 0635:30 UT and subsequently moved poleward at a speed of $\sim 1.5 \mathrm{~km} \mathrm{~s}^{-1}$ (the poleward speed observed in the higher gates near the start of the event). It should be noted that with characteristic dimensions of $\sim 300 \mathrm{~km}$ the amount of magnetic flux involved was at least $5 \times 10^{6} \mathrm{~Wb}$, such that if this was opened in about $20 \mathrm{sec}$ as we suggest, the transient reconnection voltage must have exceeded $\sim 200 \mathrm{kV}$.

The straight lines and dots then indicate the proposed locations of the centres of gates 1 to 5 at the beginning and end of each of the two dwell periods in which the first burst perturbation was observed (i.e. 0635:30 UT to 0637:30 at azimuth 2 and 0638:00 to 0640:00 UT at azimuth 1). The longitudinal displacements between azimuths 1 and 2 are, of course, determined by the geometry of the experiment, while the latitudinal displacements relative to the flow pattern are drawn consistent with the assumed $\sim 1.5 \mathrm{~km} \mathrm{~s}^{-1}$ poleward motion of the corrugation. We propose that at the start of the azimuth 2 dwell at 0635:30 UT the radar line of sight lies just within the eastward border of the open field line region as shown, such that the 1-o-s flow is away from the radar at all gates. The poleward motion of the corrugation then carries the open field line boundary across the field of view, resulting in a flow reversal from poleward to equatorward as the radar observes the equatorward return flow of the external perturbation. The flow reversal will then occur at increasingly later times with increasing latitude, as observed, with the apparent speed of the reversal along the radar line of sight being determined by the angle of the boundary to the line of sight and the speed and direction of open flux tubes within the corrugation. For poleward directed motion the apparent speed of $\sim 3.5 \mathrm{~km} \mathrm{~s}-1$ requires a boundary angle of $\sim 10^{\circ}$ to the beam, as shown in Figure 2, though larger angles would be implied if the corrugation were also moving to the west, which is also consistent with our observations. With continuing poleward motion of the corrugation, equatorward flows in each gate at azimuth 2 will then clearly decline and reverse to poleward again according to Figure 2, as indeed observed in the lower gate (Figure 2). 
At the end of the azimuth 2 dwe11, Figure 2 shows weak flows away from the radar in gates 1 and 5 , with flows toward the radar in between, as required. The flow geometry then indicates that measurements at the subsequent azimuth 1 dwell should correspond to weak and declining poleward flows, in conformity with the data in Figure 1. After this we would expect the flow to return to its previous almost stagnant state. However, the new burst activity observed on return to azimuth 2 at about 0641 UT is consistent with a similar, though more slowly-moving twin-vortex perturbation and indicates that the open field boundary had once more expanded rapidly equatorward, due to a second burst of reconnection.

It is recognized that our interpretation of the main flow burst data at azimuth 2 relies on the assumption of a rather special location relative to the model flow perturbation shown in Figure 2. However, other signatures consistent with this flow pattern have also been observed, including examples of exclusively poleward flow as would be expected from Figure 2. To date no cases of predominantly equatorward flow have been observed, as predicted by the impulsive penetration picture.

Summary

EISCAT POLAR observations have been presented of two highly structured, short-lived flow bursts which occurred in the high latitude dayside ionosphere equatorward of the region where auroral zone flows enter the polar cap. The bursts occurred under conditions of moderate magnetic activity when IMF $B_{z}$ was near zero. The main burst exhibited peak poleward flows of $\sim 1.5$ to $2 \mathrm{~km} \mathrm{~s}^{-1}$, a time scale for variations of 1 to $2 \mathrm{~min}$, a total duration of $\sim 5 \mathrm{~min}$ and a probable spatial scale of $\sim 300 \mathrm{~km}$. It has been shown that the bursts can be consistently accounted for in terms of an ionospheric perturbation caused by localized impulsive reconnection at the magnetopause, following the theoretical discussion of Cowley (1984) and Southwood (1985).

Acknowledgments. This work was performed while H.T. was supported by a UK SERC Studentship. We would like to thank Dr D.J. Southwood for provision of the AMPTEUKS magnetometer data and Drs R.P. Rijnbeek and W.A.C. Mier-Jedrzejowicz for aid in its processing. We would also like to thank the Director and staff of EISCAT for their help. EISCAT is supported by the United Kingdom SERC, French CNRS, West German MPG, Norwegian NAVF, Swedish NFR, and Finnish SA.

\section{References}

Cowley, S.W.H., The causes of convection in the Earth's magnetosphere: A review of developments during the IMS, Rev. Geophys. Space Phys., 20, 531, 1982.
Cowley, S.W.H., Evidence for the occurrence and importance of reconnection between the Earth's magnetic field and the interplanetary magnetic field, in Magnetic Reconnection in Space and Laboratory Plasmas, Geophysical Monograph 30, AGU, Washington DC, p.375, 1984.

Cowley, S.W.H., The impact of recent observations on theoretical understanding of solar-wind magnetosphere interactions, J. Geomag. Geoelec., in press, 1986.

van Eyken, A.P., et a1., Initial EISCAT observations of plasma convection at invariant latitudes $70^{\circ}-77^{\circ}$, J. Atmos. Terr. Phys., 46, 635, 1984.

Goertz, C.K., et al., Observations of a possible ground signature of flux transfer events, J. Geophys. Res., 90, 4069, 1985.

Lundin, R., and E. Dubinin, Solar wind energy transfer regions inside the dayside magnetopause - I. Evidence for magnetosheath plasma penetration, Planet. Space Sci., 32, $745,1984$.

Paschmann, G., et al., Plasma and magnetic field characteristics of magnetic flux transfer events, J. Geophys. Res., 87, 2159,1982

Rijnbeek, R.P., et al., A survey of dayside flux transfer events observed by the ISEE-1 and -2 magnetometers, J. Geophys. Res., 89 , 786,1984 .

Rishbeth, H., et al., Ionospheric response to changes in the interplanetary magnetic field observed by EISCAT and AMPTE UKS, Nature, 318, 451, 1985.

Russell, C.T., and R.C. Elphic, ISEE observations of flux transfer events at the dayside magnetopause, Geophys. Res. Lett., $6,33,1979$.

Sckopke, N., et al., Structure of the low latitude boundary layer, J. Geophys. Res., 86, 2099, 1981.

Sonnerup, B.U.ö., et a1., Evidence for magnetic field reconnection at the Earth's magnetopause, J. Geophys. Res., 86, 10049, 1981.

Southwood, D.J., Theoretical aspects of ionosphere-magnetosphere-solar wind coupling, Adv. Space Res., 5, 4-7, 1985.

Willis, D.M., et al., A survey of simultaneous observations of the high-latitude ionosphere and interplanetary magnetic field with EISCAT and AMPTE-UKS, submitted to J.Atmos. Terr. Phys., 1986.

H. Todd and S.W.H. Cowley, Blackett Laboratory, Imperial College, London SW7 2BZ, UK.

B.J.I. Bromage, M. Lockwood, D.M. Willis, Rutherford Appleton Laboratory, Chilton, Didcot, Oxon, OX11 OQX, UK.

A.P. van Eyken, Millstone Hill Radar, MIT Haystack Observatory, Westford, MA 01886, USA.
(Received June 9, 1986; accepted June 19, 1986). 